\title{
KESIAPAN KONDISI FISIK ATLET SELAM DRAGON WIRA YUDHA DALAM PERSIAPAN SELEKSI PORPROV KOTA KEDIRI 2021
}

\author{
Imam Sugeng ${ }^{1}$, Rendhitya Prima Putra ${ }^{2}$ \\ 1 Universitas Kahuriapan Kediri \\ ZUniversitas Nusantara PGRI Kediri \\ E-mail: imamsugeng@kahuripan.ac.id¹, rendhitya1407@gmail.com² \\ DOI: https://doi.org/10.36526/kejaora.v6i2.1515
}

\begin{abstract}
ABSTRAK
Kondisi fisik sangat berperan dalam performa terbaik atlet menyelam (finswimming). Jika anda dalam kondisi fisik yang baik, anda dapat membantu atlet berlatih dan berpartisipasi dalam kompetisi. Oleh karena itu, atlet perlu mengetahui pentingnya kebugaran jasmani sebagai indikator pencapaian prestasi. Penelitian ini bertujuan untuk mengetahui tingkat kesegaran jasmani (endurance) atlet selam Dragon Wira Yudha Kota Kediri menuju seleksi Porprov 2021. Pendekatan pada penelitian ini mengunakan pendekatan deskriptif kuantitatif. Dalam studi semacam itu, tidak perlu mempertimbangkan hubungan antar variabel. Sampel untuk penelitian ini termasuk 11 atlet. Hasil penelitian menunjukkan daya tahan aerobik atlet putra dan putri Naga Wira Yudha peserta seleksi Porprov Kota Kediri dalam kategori sedang dan kapasitas VO2max yaitu level 8 shuttle 5 putra dan level 9 shuttle 6 untuk atlet wanita.
\end{abstract}

Kata Kunci: Vo2max, Finswimming,Dragon Wira Yudha

\section{PENDAHULUAN}

Porprov adalah suatu ajang bergengsi yang dilaksankan setiap 2 tahun sekali di JawaTimur. setiap daerah akan berlombalomba untuk mendapatkan mendalai emas terbayak sehingga menjadi juara umum salah satunya adalah Kota Kediri. Kota Kediri tahun 2019 menjadi peringkat 3 besar di ajang tersebut, penyumbang mendali terbanyak yaitu wushu, bolavoli, senam, atletik, renang dan selam. Dalam mempersiapan kejuaraan tersebut dan mendapatkan atlet terbaik, Kota Kediri mengadakan seleksi setiap cabor yang akan di pertandingakan di ajang Porprov yaitu salah satunya adalah selam.

Keugaran merupakan faktor kunci yang harus dimiliki seorang atlet untuk mencapai performa teraik. Pernyataan ini dikuatkan oleh (Pujianto., 2015) Kondisi fisik diperlukan atlet untuk meningkatkan dan mengembangkan prestasi, oleh karena itu harus dikembangkan dan ditingkatkan sesuai dengan karakter kebutuhan cabang olahraga. Sedangkan Moskovchenko et al., (2019) untuk mendukung performa teraik kondisi fisik dalam menyelam sangat diutuhkan untuk mendukung pelaksanaan teknik dan taktik selama latihan atau kompetisi. Dapat disimpulkan ahwa keugaran memainkan peran yang sangat penting dalam meningkatkan pengemangan teknik taktis selama pelatihan dan kompetisi untuk mencapai efisiensi maksimum. Hasil observasi dengan pelatih Yanuar Risky menunjukkan ahwa di klu Dargon Wira Yudha perenang naga Wira Yudha Kediri tidak pernah melakukan pengukuran keugaran secara erkala untuk menunjang prestasi yang akan dipersiapkan untuk seleksi Porprov 2021. Pengukuran ini harus dilakukan secara berkala mengingat potensi esar para atlet yang tergaung dalam klu Naga Wira Yudha.. Tujuan penelitian ini untuk mengetahui tingkat kondisi fisik (enduracen) Atlet Selam (finswiimming) klub dragon wira yudha menuju seleksi Porprov 2021.

\section{METODE}

Penelitian ini menggunakan penelitian deskriptif kuantitatif, metode deskriptif kuantitatif adalah suatu pendekatan yang menggunakan angka dan statistik sebagai 
Jurnal Kejaora: Jurnal Kesehatan Jasmani dan Olah Raga

ISSN: 2541-5042 (Online)

ISSN: 2503-2976 (Print)

Volume 6 Nomor 2, Edisi November 2021

alat untuk pengolahan data dan pengambilan keputusan yang mendasar karena dalam penelitian ini terdapat beberapa kecenderungan karakteristik dari metode kuantitatif (Arikunto, 2014). Survei digunakan untuk mengukur gejala yang ada tanpa menyelidiki mengapa gejala itu terjadi. Dalam penelitian seperti itu, kita tidak perlu memperhitungkan hubungan antar variabel Sampel dalam penelitian ini adalah 10 atlet.

Instrumen adalah metode yang digunakan untuk mengumpulkan data yang diutuhkan peneliti. Dalam penelitian ini, peneliti menggunakan tes kebugaran Aerobic endurance menggunakan multistage fitness test (MFT)

Teknik analisis data dalam penelitian ini Pengolahan data untuk penelitian ini menggunakan metode analisis data dengan rumus sebagai berikut: :

1. Rata-rata Hitung (Mean)

$$
\begin{aligned}
& \text { Rumus : } M=\frac{\sum X}{n} \\
& \text { Keterangan : }
\end{aligned}
$$

$\begin{array}{ll}\mathrm{M} & \text { : Rata-rata } \\ \Sigma \mathrm{x} & \text { : Jumlah Nilai X } \\ \mathrm{n} & \text { : Jumlah Subyek }\end{array}$

2. Menghitung Standart Deviasi (Simpangan Baku)

\section{HASIL DAN PEMBAHASAN}

Berdasarkan sejumlah penelitian erturut-turut erupa tujuan penelitian terhadap kondisi fisik (daya tahan) atlet loncat indah yang didukung oleh Klu Dragon Wira Yudha Kediri yang akan mengikuti seleksi pilih porprov 2021 akan diuraikan data deskripsi . Data yang disajikan adalah yang diperoleh dari pengujian dan pengukuran yaitu:: Aeroic endurance diving (fin swimming) Dragon Wira

Yudha yang akan mengikuti seleksi Porprov 2021 di Kota Kediri.1.

\section{Aerobic Endurance Putra}

Berdasarkan hasil pengukuran Aerobic endurance dengan memakai teknik (MFT) atlet Dragon Wira Yudha dengan usia 14-16 tahun katagori putra, berikut ini deskripsi hasil tes yang diperoleh atlet putra Dragon Wira Yudha nilai maksimum $=50,8$; nilai minimum $=38,6$; rerata $=44,67$; standar deviasi $=5,00$; modus $=42,6$; dan median $=$ 42,6 untuk kategori Fair $(66,70 \%)$, good $(33,30 \%)$ sedangkan untuk kategori very good dan excellen ( $0 \%)$. Berikut tabel statistik deskriptif aerobic endurance yang diperoleh.

Tabel 1.Hasil Tes MFT

\begin{tabular}{lllll}
\hline NO & Nama & Level & Score & Kategori \\
\hline 1 & SH & L11 S2 & 50.8 & Good \\
\hline 2 & Al & L8 S9 & 42.6 & Fair \\
\hline 3 & AD & L8 S9 & 42.6 & Fair \\
\hline 4 & FM & L11 S2 & 50.8 & Good \\
\hline 5 & LP & L8 S9 & 42.6 & Fair \\
\hline 6 & VR & L7 S1 & 38.6 & Fair \\
\hline
\end{tabular}

Tabel 2. Statistik Deskriptif Aerobic Endurance

\begin{tabular}{lll}
\hline No & Tendensi Sentral & Hasil \\
\hline 1 & Nilai Maksimum & 50,8 \\
\hline 2 & Nilai Minimum & 38,6 \\
\hline 3 & Rerata & 44,67 \\
\hline 4 & Standart Deviasi & 5,00 \\
\hline 5 & Modus & 42,7 \\
\hline 6 & Median & 42,6 \\
\hline
\end{tabular}


Jurnal Kejaora: Jurnal Kesehatan Jasmani dan Olah Raga

ISSN: 2541-5042 (Online)

ISSN: 2503-2976 (Print)

Volume 6 Nomor 2, Edisi November 2021

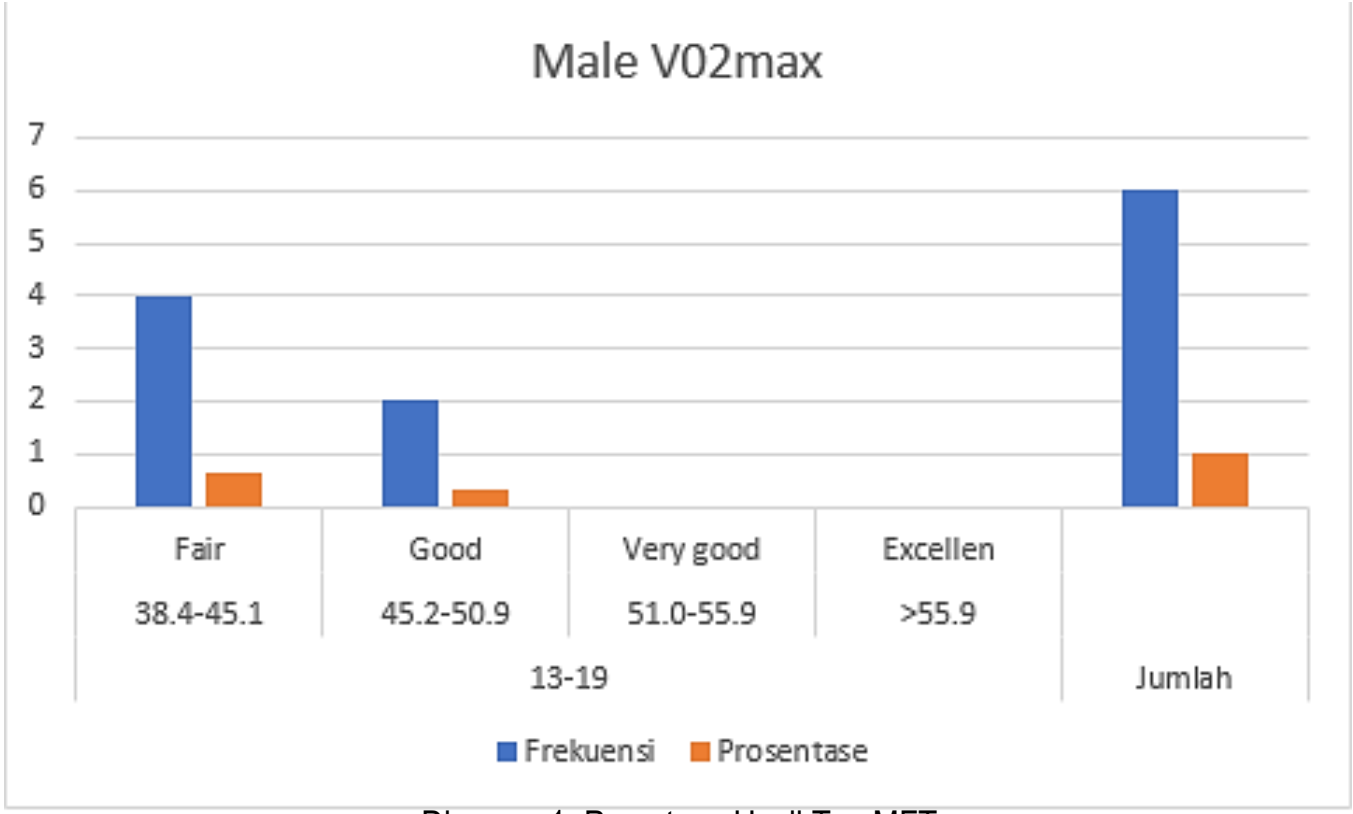

Diagram 1. Prosetase Hasil Tes MFT

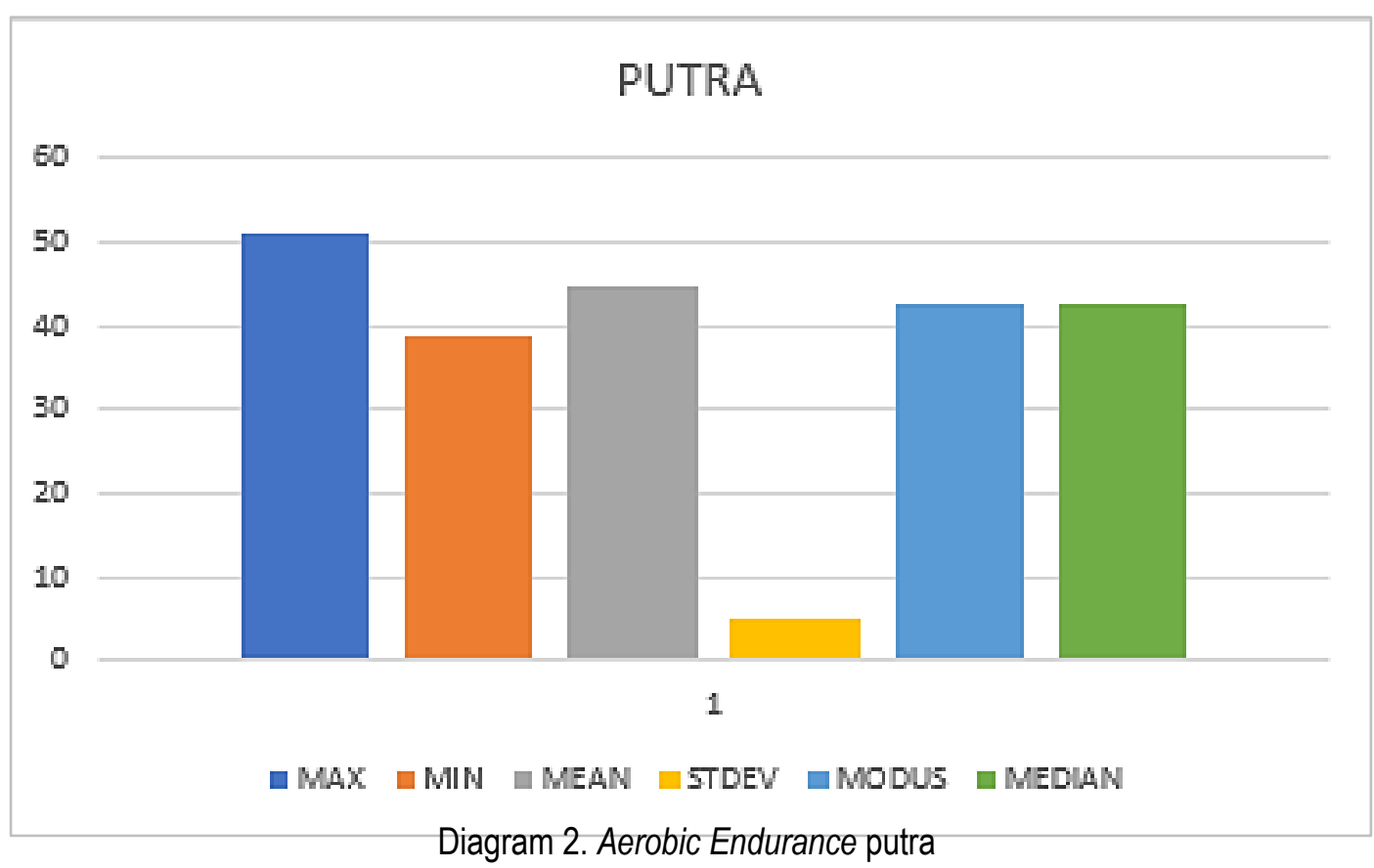

\section{Aerobic Endurance Putri}

Berdasarkan hasil pengukuran Aerobic endurance dengan menggunakan pengukuran multistage fitness test (MFT) atlet Dragon Wira Yudha dengan usia 14-16 tahun katagori putri , berikut ini deskripsi hasil tes yang diperoleh atlet putra Dragon Wira Yudha nilai maksimum $=50,2$; nilai minimum $=41,2$; rerata $=45,15$; standar deviasi $=5,00$; modus
$=42,6$; dan median $=42,6$, untuk Kategori fair $(60 \%)$, good $(40 \%)$ sedangkan untuk kategori very good dan excellen $(0 \%)$. Berikut tabel statistik deskriptif aerobic endurance yang diperoleh. 
Jurnal Kejaora: Jurnal Kesehatan Jasmani dan Olah Raga

ISSN: 2541-5042 (Online)

ISSN: 2503-2976 (Print)

Volume 6 Nomor 2, Edisi November 2021

Tabel 3. Hasil Test MFT Putri

\begin{tabular}{lllll}
\hline No & Nama & Level & Score & Kategori \\
\hline 1 & RR & L10 S11 & 50.2 & Good \\
\hline 2 & VN & L9 S3 & 44.2 & Fair \\
\hline 3 & SK & L9 S7 & 45.5 & Good \\
\hline 4 & KZ & L9 S3 & 44.2 & Fair \\
\hline 5 & GS & L8 S6 & 41.8 & Fair \\
\hline
\end{tabular}

Tabel 4. Statistik Deskriptif Aerobic Endurance putri

\begin{tabular}{lll}
\hline No & Tendensi Sentral & Hasil \\
\hline 1 & Nilai Maksimum & 50,8 \\
\hline 2 & Nilai Minimum & 38,6 \\
\hline 3 & Rerata & 44,67 \\
\hline 4 & Standart Deviasi & 3,11 \\
\hline 5 & Modus & 44,2 \\
\hline 6 & Median & 44,2
\end{tabular}

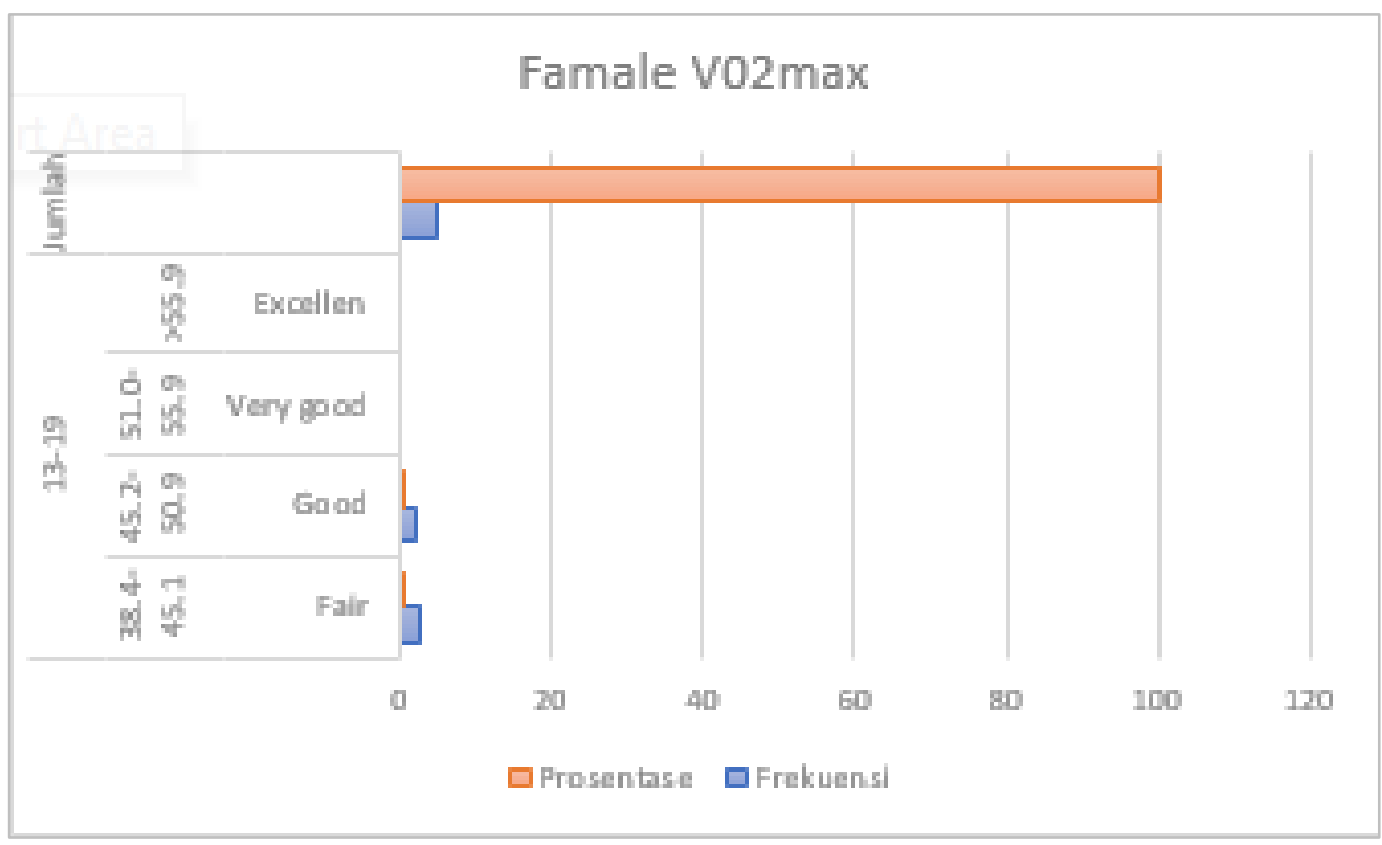

Diagram 3. Prosentase Hasil MFT Putri

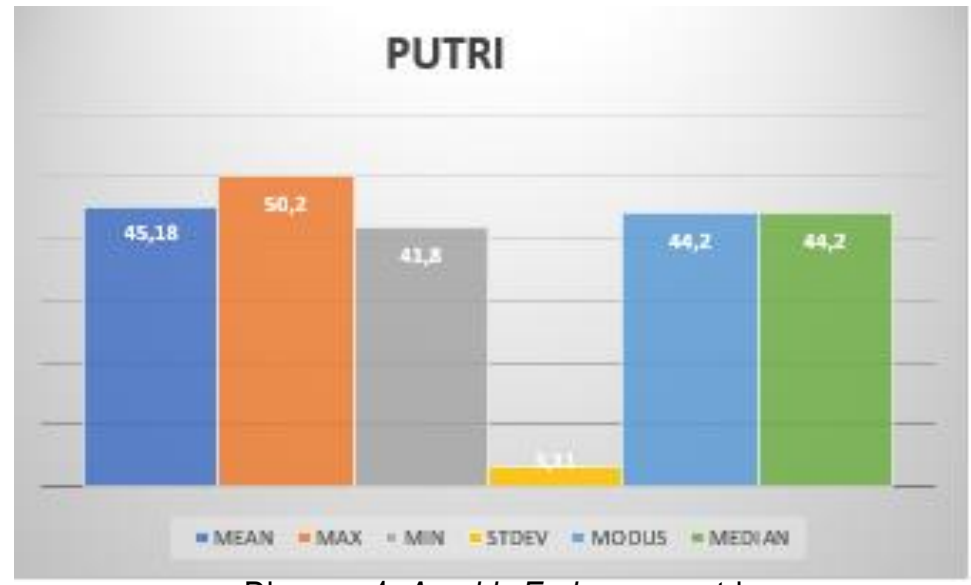

Diagram 4. Aerobic Endurance putri 
Jurnal Kejaora: Jurnal Kesehatan Jasmani dan Olah Raga

ISSN: 2541-5042 (Online)

ISSN: 2503-2976 (Print)

Volume 6 Nomor 2, Edisi November 2021

Berdasakan hasil di atas dapat di rinci bahwa atlet putra dan putri Dragon Wira Yudha yang akan mengikuti ajang seleksi Porprov pada cabang olahraga selam (finswimming) Kota Kediri dapat di katakan kemampuan kondisi fisik harus di tingkatkan lebih baik lagi (Baly et al., 2001). Sedangkan kemampuan kondisi fisik yang harus dimiliki oleh atlet setiap komponennya harus berada dalam kategori baik atau baik sekali selaras dengan yang di sampaikan (Hue et al., 2006) bahwa rata-rata VO2max finswimmer ialah $47,5 \mathrm{ml} / \mathrm{kg} / \mathrm{min}$, pada setiap komponen.

\section{PEMBAHASAN}

Seorang atlet di tuntut memiliki kondisi fisik dengan kategori baik atau baik sekali, dengan tujuan atlet tersebut dapat memiliki potensi untuk berprestasi di cabang olah raga yang di pertandingkan sesuai dengan cabang olahraga yang di ikuti atlet tersebut, pernyataan tersebut di kuatkan teori (Taya et al., 2019) yaitu kapasitas respiratori dapat dipengaruhi oleh karakteristik latihan dan jenis cabang olahraga. Maka dari itu seluruh atlet binaan yang di siapakan untuk mengikuti ajang perlombaan harus meningkatkan kondisi fisiknya dan mengembangkan semua aspek komponen kondisi fisik secara seimbang dengan tidak melupakan aspek komponen kondisi fisik yang memiliki perananan penting dalam nomor lomba yang di ikuti atau dipilih.

\section{KESIMPULAN}

Dari hasil analisis data tingkat kondisi fisik masing-masing atlet puta dan putri klub Dragon Wira Yudha kediri yang akan megikuti seleksi Porprov pada cabang olahraga selam (finswimming) memiliki perbedaan antara satu dengan yang lainya. Berdasarkan analisis dan pembahasannya, maka dapat ditarik simpulan secara keseluruhan tingkat kondisi fisik atlet pada cabang olahraga selam (finswimming) kota kediri dari hasil parameter tes menunjukkan bahwa Aerobic endurance atlet putra dan putri klub dragon wira yudha kediri pada cabang olahraga selam (finswimming) mayoritas dikategorikan dengan rata-rata SEDANG dengan level putra 8 shuttle 5 sedangkan untuk atlet putri level 9 shuttle 6 kapasitas aerobic (VO2MAX). 